\title{
Effects of Ginger for Nausea and Vomiting in Early Pregnancy: A Meta-Analysis
}

\author{
Maggie Thomson, MD, Renee Corbin, MSc, and Lawrence Leung, MBBChir, MFM(Clin)
}

Background: Nausea and vomiting in early pregnancy (NVEP) is commonly encountered in family medicine. Ginger (Zingiber officinale) is a popular nonpharmacological treatment but consensus of its use is lacking.

Methods: We conducted a meta-analysis of clinical trials using ginger for NVEP as published in PubMed and EMBASE, CINAHL, Cochrane Library, and all EBM reviews. Studies satisfying 3 criteria were selected: (1) randomized placebo-controlled design; (2) use of ginger or Z. officinale; and (3) extractable data on improvement in NVEP. Data were synthesized into pooled odd ratios based on the random effects model, and results were tabulated with the aid of Forest plots.

Results: We identified 135 potentially relevant records; only 6 studies met the final criteria. Of the total 508 subjects, 256 and 252 subjects were randomly assigned to receive ginger and placebo, respectively. The use of ginger ( $\sim 1 \mathrm{~g}$ daily) for at least 4 days is associated with a 5 -fold likelihood of improvement in NVEP. Heterogeneity among the clinical studies were acknowledged in the final interpretation of results.

Conclusions: Despite the widespread use of ginger in the diet, its clinic value and safety profile in treating NVEP is still unknown. Our meta-analysis suggests that ginger is an effective nonpharmacological treatment for NVEP. (J Am Board Fam Med 2014;27:115-122.)

Keywords: Alternative Medicine, Complementary Medicine, Pregnancy, Prenatal Care, Primary Health Care

Pregnancy-induced nausea and vomiting is commonly seen in family medicine, and $50 \%$ to $90 \%$ of pregnancies are affected by nausea with or without vomiting. According to a recent study, up to $63 \%$ of women experience nausea and vomiting up to 24 weeks' gestation. ${ }^{1}$ While only $0.3 \%$ to $2 \%$ of these cases are considered severe (called hyperemesis gravidarum, leading to a loss of $>5 \%$ of prepregnancy body weight), all forms of pregnancy-related nausea can affect quality of life. ${ }^{2}$ Compared with the volume of literature regarding the pathogenesis and treatment of pregnancy-induced nausea and

This article was externally peer reviewed.

Submitted 29 May 2013; revised 17 July 2013; accepted 22 July 2013.

From the Department of Family Medicine (MT, LL) and the Centre of Studies in Primary Care (RC, LL), Queen's University, Kingston, Ontario, Canada.

Funding: none.

Conflict of interest: none declared.

Corresponding author: Lawrence Leung, MBBChir, MFM(Clin), Department of Family Medicine, Queen's University, 220 Bagot St, PO Bag 8888, Kingston ON K7L 5E9, Canada (E-mail: leungl@queensu.ca). vomiting in general, few studies look at nausea and vomiting in early pregnancy (NVEP).

\section{Epidemiology, Risk Factors, and Pathogenesis of NVEP}

Nausea and vomiting during pregnancy is known to be more common in younger primigravid women, as well as in Western countries and urban areas. ${ }^{2}$ Risk factors for its development include history of estrogen-based medication causing nausea and motion or migraine causing nausea. Multiple gestation pregnancies, ${ }^{3}$ women who did not take multivitamins before conception, ${ }^{4}$ those with acid reflux, ${ }^{5}$ and those with a hydatidiform mole ${ }^{6}$ also are known be at increased risk. There seems to be a genetic component to developing hyperemesis gravidarum; several studies demonstrate that daughters of women who experienced the condition are at increased risks. ${ }^{7,8}$ It is interesting that alcohol consumption and cigarette smoking have both been demonstrated to be protective. ${ }^{9}$ The exact pathogenesis of NVEP remains unclear; however, hormonal changes including elevated serum human chorionic gonado- 
tropin have been implicated, ${ }^{2}$ as have psychological factors and stress response. ${ }^{10}$ Delayed or dysrhythmic gastric motility also has been postulated as a likely cause of NVEP. ${ }^{2}$

\section{Diagnosis and Treatment of NVEP}

Diagnosis of NVEP is purely clinical. There exists no defined diagnostic criteria for the condition. Mean onset is known to be between 5 to 6 weeks of gestation, with the majority of symptoms resolving by 20 weeks. ${ }^{2}$ Approximately $20 \%$ of women continue to have symptoms into their second and third trimesters. ${ }^{2}$ Contrary to popular belief, symptoms occur throughout the day and are often not limited to the morning as the term morning sickness would imply. ${ }^{2}$

Goals of treatment include reducing maternal symptoms and complications and mitigating any effects on the fetus. Antiemetics for NVEP that have been studied include Diclectin (Duchesnay Inc., Blainville, QC, Canada), ondansetron, ginger, various antihistamines, vitamin $\mathrm{B}_{6}$, metoclopramide, and phenothiazines. ${ }^{2}$ A recent randomized, double-blind, placebo-controlled trial ${ }^{11}$ demonstrated that Diclectin was effective for nausea and vomiting during pregnancy, and this drug is currently recommended as first-line pharmacological treatment for NVEP in Canada. Ondansetron is commonly used as an antiemetic during chemotherapy, with good evidence. ${ }^{12}$ However, it has been used for some time in the United States as a first-line (albeit off-label) treatment for pregnancy-related nausea and vomiting. ${ }^{13}$ While evidence exists for other pharmacological and nonpharmacological treatments (eg, dietary adjustments, acupressure, and acupuncture), they are beyond the scope of this article. Our study aimed to critically examine the efficacy of ginger in the treatment of NVEP through meta-analysis of published clinical trials.

\section{Ginger and Its Medicinal Effects}

The antinausea effect of ginger was first described in one of the canons of traditional Chinese medicine-the Synopsis of the Prescriptions of Golden Chamber ${ }^{14}$-in 200 AD. Ginger is the underground stem (or rhizome) of the perennial plant Zingiber officinale, which is indigenous to China and India but is cultivated all over the world. From the body of ginger sprouts the peudostems, which branch off to leaves that can reach 2 feet in height. ${ }^{15}$ Analysis of ginger reveals 2 major classes of phytochemicals: volatile oils, which give ginger its pleasant smell, ${ }^{16}$ and the nonvolatile compounds (eg, gingerols and zingerones), which account for its piquant taste and its pharmacological effects. ${ }^{17}$ Many studies of the antiemetic nature of ginger for various conditions have been published but with mixed results. While evidence supports benefits of ginger for seasickness, ${ }^{18}$ motion sickness, ${ }^{19}$ and postoperative nausea and vomiting, ${ }^{20}$ its use in preventing chemotherapy-induced nausea and vomiting is still conflicting. ${ }^{21,22}$ Ginger also has been demonstrated to be effective in treating nausea and vomiting in pregnancy to the extent that it is as effective as vitamin $\mathrm{B}_{6}$ alone. ${ }^{23-27}$ The exact antiemetic mechanisms of ginger are still unknown, but in vitro studies revealed antagonistic effects of gingerols on serotonergic $5-\mathrm{HT}_{3}{ }^{28,29}$ and cholinergic $\mathrm{M}$ receptors. ${ }^{29}$ So far, no direct adverse effects on human fetuses or the course of pregnancy have been demonstrated. ${ }^{24-27}$ However, there had been concerns about interfering with fetal development, which led to the issuance within Finland and Denmark of warning labels for all supplements containing ginger. ${ }^{30}$ It is also recognized that ginger has potent anticoagulant effects, which may enhance bleeding and miscarriages and interact with other medications. ${ }^{30}$ At present, there are no large-scale studies ascertaining the safety of ginger. That said, in Europe and North America the current consensus for the maximum safe dose of ginger is $2 \mathrm{~g}$ /day in divided doses of $250 \mathrm{mg}$, even during pregnancy. ${ }^{30}$

\section{Methods}

Study Aim

NVEP is a commonly encountered condition in family medicine, and ginger has been used as a nonpharmacological remedy. Our meta-analysis aimed to critically examine and synthesize available data from good-quality randomized clinical trials to evaluate the efficacy of ginger in treating NVEP.

\section{Eligibility Criteria}

Our primary interest was the treatment of NVEP using ginger as the therapeutic intervention. To minimize heterogeneity, we limited our scope to randomized, placebo-controlled trials with a satis- 
factory score on the Cochrane Risk of Bias assessment tool.

\section{Search Strategy}

A literature search of published medical reports was performed in all languages using PubMed, EMBASE, CINAHL, the Cochrane Library, and all evidence-based medicine reviews using the OVID Portal of Queen's University, Kingston, Ontario. Abstracts were initially obtained using $\mathrm{MeSH}$ keywords of early pregnancy, nausea, vomiting, and ginger. Manual searches of references and review articles supplemented the computerized search.

\section{Study Selection, Data Extraction, and Quality Assessment}

Two reviewers (MT and $\mathrm{RC}$ ) went through the initial abstracts. A simple form was adopted to select trials that satisfied the eligibility criteria stated above. Selected studies were evaluated according to the Cochrane Risk of Bias tool with regard to quality of the study, randomization protocol, adequacy of concealment and blinding, and rigor of follow-up for drop-outs. Information regarding the demography of the study population, duration of the study, the number of affected subjects who improved with treatment and placebo, and finally a numeric score for the Cochrane risk of bias was extracted and tabulated in spreadsheets. Of note, we found only 6 randomized, placebo-controlled trials of ginger that displayed data required for our meta-analysis (see Table 1). The primary outcome was improvement of pregnancy-related nausea and vomiting.

\section{Statistical Analysis}

All data from the 6 appropriate studies of ginger were synthesized in a meta-analysis, and odds ratios (ORs) were calculated with appropriate confidence intervals (CIs) based on the number of subjects reporting improvement in both the intervention and control groups. Where necessary, the value of 1 was added to any arm with zero outcome events according to the Sheele +1 rule. To assess heterogeneity, we used the Cochrane Q-statistic with $95 \%$ confidence CIs. We assumed a $P$ value of $<.05$ for the Cochran Q-statistic. Forest plots were generated with ORs for each ginger study. Statistical advice was provided by our data analyst at our Centre of Studies in Primary Care.

\section{Results}

We initially identified 135 records using the MeSH keywords of early pregnancy, ginger, nausea, and vomiting. After removing duplicates and further screening, 8 full articles were retrieved. Two of them were excluded because of irrelevance. Consensus was reached among the reviewers to include the final 6 studies. The 2009 PRISMA checklist was used; the PRISMA flow diagram is given in the Appendix.

In our meta-analysis, a total of 256 patients were randomly assigned to receive ginger, and $252 \mathrm{pa}$ tients were randomly assigned to receive placebo. Total sample size per study ranged from 23 to 235 . The period of intervention lasted from 4 days to 3 weeks. Dose and method of administration of ginger also varied among studies: Basirat et $\mathrm{al}^{31}$ used 5 biscuits per day, each containing $500 \mathrm{mg}$ of ginger,

Table 1. Brief Description of the 6 Studies Included in the Meta-Analysis

\begin{tabular}{|c|c|c|c|c|c|}
\hline Study & Intervention & Placebo & $\begin{array}{l}\text { Duration of } \\
\text { Study }\end{array}$ & $\begin{array}{l}\text { Gestation } \\
\text { Stage }\end{array}$ & $\begin{array}{c}\text { Outcome Measure (Nausea } \\
\text { and Vomiting) }\end{array}$ \\
\hline Basirat et al. ${ }^{31}$ & $\begin{array}{l}500-\mathrm{mg} \text { ginger powder in } \\
\text { biscuit, } 5 \text { biscuits/day }\end{array}$ & Placebo biscuit & 4 days & $<17$ weeks & $\begin{array}{l}\text { Nausea scale (VAS) }+ \\
\text { frequency of vomiting }\end{array}$ \\
\hline Ozgoli et al. ${ }^{35}$ & 250-mg ginger capsules QID & Lactose capsules & 4 days & $<20$ weeks & $\begin{array}{l}\text { Nausea scale (VAS) }+ \\
\quad \text { frequency of vomiting }\end{array}$ \\
\hline Smith et al. ${ }^{26}$ & 350-mg ginger capsules TID & $\begin{array}{l}\text { Vitamin } B_{6}(25- \\
\text { mg capsules })\end{array}$ & 3 weeks & $<16$ weeks & $\begin{array}{l}\text { Nausea and vomiting scales } \\
\text { (Rhodes Index) }\end{array}$ \\
\hline Keating et al. ${ }^{32}$ & 250-mg ginger syrup QID & Plain syrup & 2 weeks & $<12$ weeks & $\begin{array}{l}\text { 4-point nausea scale }+ \\
\text { frequency of vomiting }\end{array}$ \\
\hline Vutyavanich et al. ${ }^{34}$ & 250-mg ginger capsules QID & Placebo capsules & 4 days & $<17$ weeks & VAS + Likert scale \\
\hline $\begin{array}{l}\text { Fischer-Rasmussen } \\
\text { et al. }\end{array}$ & 250-mg ginger capsules QID & Lactose capsules & 4 days & $<20$ weeks & Unique scoring system \\
\hline
\end{tabular}

QID, four times per day; TID, three times per day; VAS, visual analogue scale. 
Table 2. Results from Meta-Analysis Comparing Ginger to Placebo in Improvement of Nausea and Vomiting in Early Pregnancy

\begin{tabular}{|c|c|c|c|c|}
\hline Study & Intervention Group & Control Group & Odds Ratio & $95 \%$ CI \\
\hline Basirat et al. ${ }^{31}$ & $28 / 32$ & $21 / 30$ & 3.00 & $0.81-11.1$ \\
\hline Fischer-Rasmussen et al. ${ }^{33}$ & $19 / 27$ & $4 / 27$ & 13.66 & $3.56-52.43$ \\
\hline Keating et al. ${ }^{32}$ & $10 / 13$ & $2 / 10$ & 13.33 & $1.78-100.14$ \\
\hline Vutyavanich et al. ${ }^{34}$ & $28 / 32$ & $10 / 35$ & 17.50 & $4.87-62.87$ \\
\hline Ozgoli et al. ${ }^{35}$ & $27 / 32$ & $20 / 35$ & 4.05 & $1.26-12.99$ \\
\hline Smith et al. ${ }^{26}$ & $68 / 120$ & $69 / 115$ & 0.87 & $0.52-1.47$ \\
\hline Total (random effects) & $180 / 256$ & $126 / 252$ & 4.89 & $1.88-12.73$ \\
\hline
\end{tabular}

CI, confidence interval.

whereas the others used either capsules or syrup containing approximately $1 \mathrm{~g}$ of ginger daily ${ }^{26,32-35}$ (Table 1).

We applied the Cochrane Risk of Bias assessment to the 6 studies; they achieved a score of at least 3 of 6 and were deemed to be of satisfactory quality.

Our primary outcome was the improvement of pregnancy-related nausea and vomiting, which was reported in all 6 studies: 180 of the 256 subjects in the ginger group and 126 of the 252 subjects in the placebo group reported improvement in symptoms of nausea and vomiting. In view of the interstudy variation in the duration and form of intervention, a random effects model was adopted. The pooled OR was 4.89, with a $95 \% \mathrm{CI}$ of 1.88 to 12.73 (see Table 2). The Cochrane Q-statistic was significant at 33.72, with a degree of freedom of $5(P<.0001)$ (Table 3$)$. A synthesis Forest plot was generated (Figure 1), and the corresponding funnel plot is included for reference (Figure 2). Relative risk was calculated at 1.76 (95\% CI, 1.18-2.65), and the number needed to treat for a positive effect was calculated to be 5 .

\section{Discussion}

Our meta-analysis demonstrated that ginger ( $Z$. officinale) is better than placebo in improving NVEP when administered at a dosage of approximately $1 \mathrm{~g} /$ day for a duration of at least 4 days.

Despite the common intake of ginger in our diet, no large-scale studies have directly assessed the safety profile of ginger during human preg-

Table 3. Test for Heterogeneity of Studies

\begin{tabular}{lc}
\hline Q-statistic & 33.72 \\
Degree of freedom & 5 \\
Significance level & $P<.0001$
\end{tabular}

nancy. In the early 1990s, Backon ${ }^{36}$ commented on a theoretical possibility of ginger affecting testosterone receptor binding and sex steroid differentiation in the fetal brain. An antiplatelet effect of ginger through inhibition of thromboxane synthetase has been reported in vitro. ${ }^{37}$ However, there have been no reports of increased risk of antenatal or postpartum hemorrhage with ginger use during pregnancy. Increased levels of early embryonic loss due to ginger intake ${ }^{38}$ were reported in rats; however, the dosage was far greater than those routinely used in humans. Subsequent study of rats using human-compatible doses of ginger showed no similar adverse effects. ${ }^{39}$

A commonly observed side effect of ginger is reflux. In a study by Willets et al, ${ }^{24} 4$ of the 120 subjects withdrew because of symptoms consistent with reflux. Reflux has been commonly reported with ginger use outside pregnancy. In a study of the prevention of postoperative nausea and vomiting, $8 \%$ of subjects had heartburn after taking $1 \mathrm{~g}$ ginger. ${ }^{40}$ Another study of photopheresis-induced nausea demonstrated that $27 \%$ of subjects has reflux as a result of ginger use. ${ }^{41}$ Apart from gastric discomfort, the side effect of reflux poses no longterm harm or damage, and patients should be warned of this side effect before beginning ginger therapy.

There are a few limitations to our meta-analysis. First, there is variability in the dosage and formulation of ginger. While 4 studies administered ginger in capsules, ${ }^{26,33-35}$ one study administered ginger in syrup $^{32}$ and the other in the form of biscuits. ${ }^{31}$ Moreover, the durations of intervention also differed. Four studies administered intervention for 4 days, ${ }^{31,33-35}$ while Keating and $\mathrm{Chez}^{32}$ gave ginger for 2 weeks and Smith et $\mathrm{al}^{26}$ for 3 
Figure 1. Forest plot for 6 studies using a random effects model. CI, confidence interval.

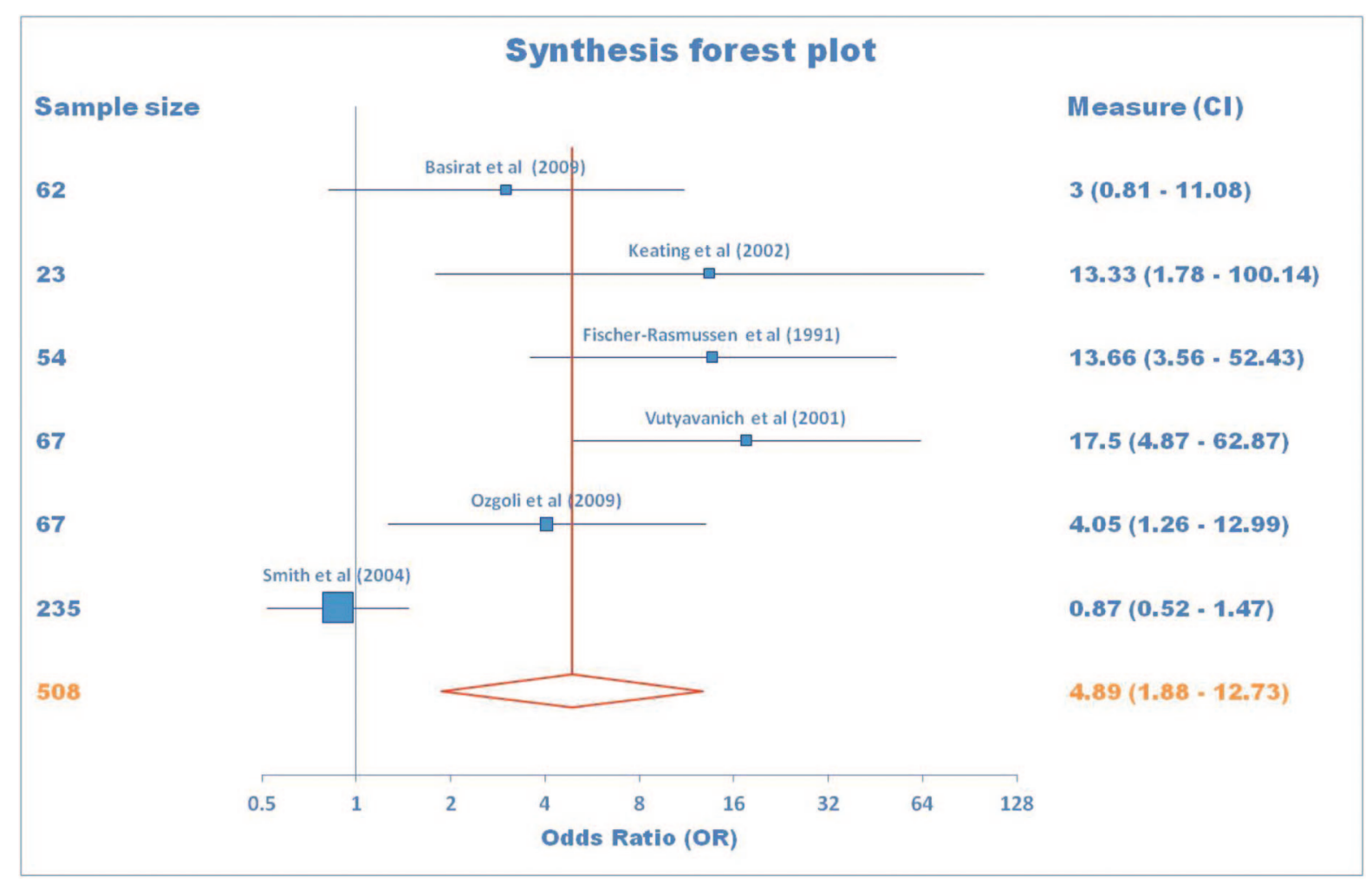

weeks. There was also variation in the combined sample size in the studies, which ranged from 23 to 235 (see Table 2). All these translated to a level of heterogeneity that was reflected in the Cochrane Q-statistic, with a significance of $P<.0001$. A final limitation of our study is the variability of scores

Figure 2. Funnel plot displaying the heterogeneity of studies. OR, odds ratio.

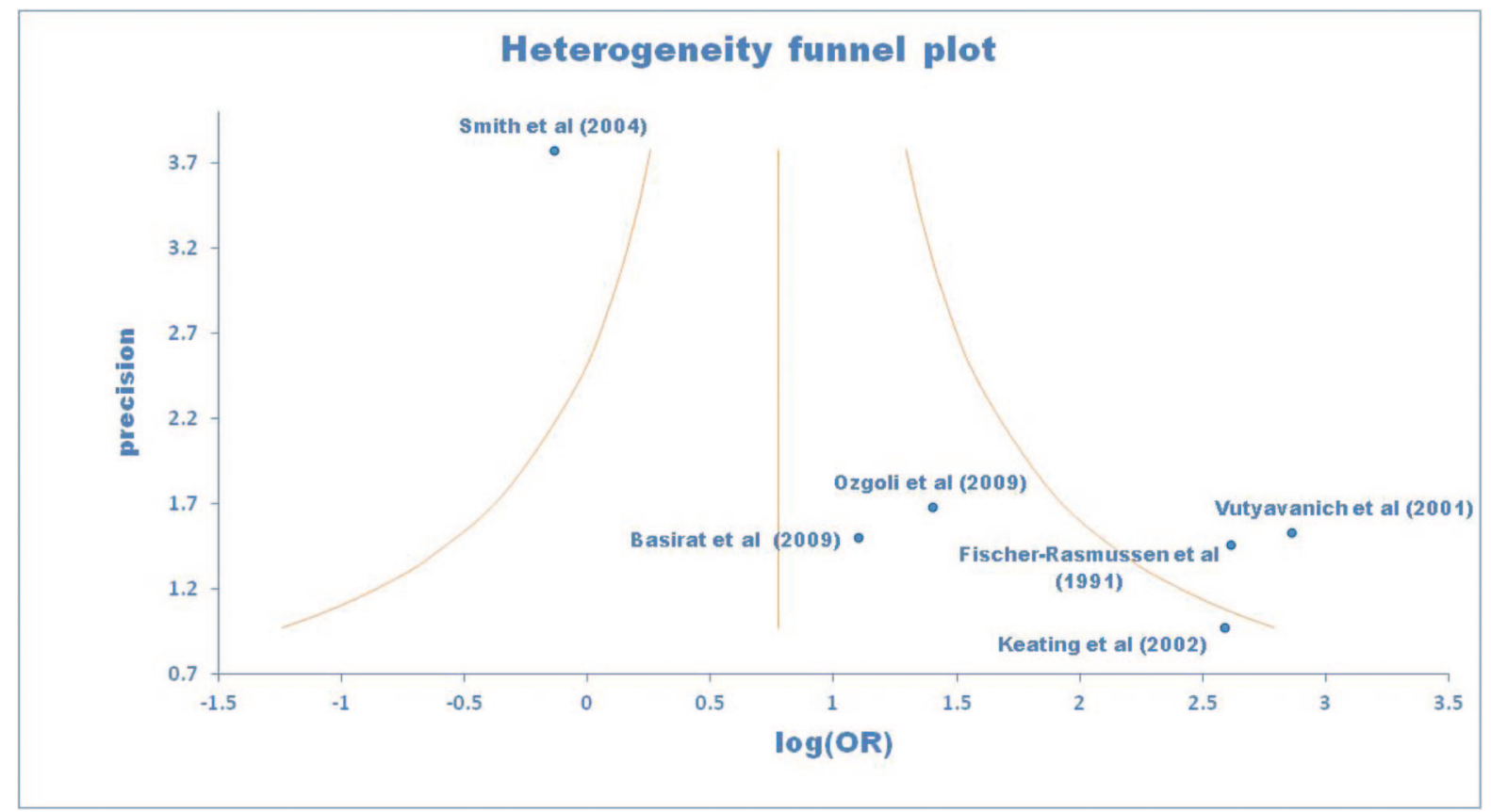


used to qualify and quantify outcome measures in NVEP. Vutyavanich et al, ${ }^{34}$ Ozgoli et $\mathrm{al},{ }^{35}$ and Basirat et $\mathrm{al}^{31}$ used a visual analog scale, whereas Fischer-Rasmussen et al $^{33}$ developed a unique scoring system. Keating and Chez used a symptoms diary and a 4-point scale and Smith et al used the Rhode's index. While this does add heterogeneity to our meta-analysis, the primary endpoint chosen remained the same (ie, improvement of NVEP).

Given its limitations, our meta-analysis demonstrated that ginger is better than placebo in improving NVEP, with an approximate number needed to treat of 5. Further large-scale, multicenter trials should be undertaken to further examine the efficacies of ginger and detail its safety profiles when treating NVEP.

\section{Conclusions}

Ginger is commonly consumed in our diet as an additive in cooking. In traditional Chinese medicine, ginger is indicated specifically as a remedy for NVEP. Based on our meta-analysis, we conclude that ginger is an effective nonpharmacological option for treating NVEP with respect to the inherent heterogeneity of the available studies. Family physicians and other medical professionals should be cognizant of the value of ginger as they contemplate pharmacological options for suitable patients with NVEP.

\section{References}

1. Kramer J, Bowen A, Stewart N, Muhajarine N. Nausea and vomiting of pregnancy: prevalence, severity and relation to psychosocial health. MCN Am J Matern Child Nurs 2013;38:21-7.

2. Lee NM, Saha S. Nausea and vomiting of pregnancy. Gastroenterol Clin North Am 2011;40:30934, vii.

3. Basso O, Olsen J. Sex ratio and twinning in women with hyperemesis or pre-eclampsia. Epidemiology 2001;12:747-9.

4. Emelianova S, Mazzotta P, Einarson A, Koren G. Prevalence and severity of nausea and vomiting of pregnancy and effect of vitamin supplementation. Clin Invest Med 1999;22:106-10.

5. Gill SK, Maltepe C, Koren G. The effect of heartburn and acid reflux on the severity of nausea and vomiting of pregnancy. Can J Gastroenterol 2009; 23:270-2.

6. Hou JL, Wan XR, Xiang Y, Qi QW, Yang XY. Changes of clinical features in hydatidiform mole: analysis of 113 cases. J Reprod Med 2008;53: 629-33.
7. Zhang Y, Cantor RM, MacGibbon K, et al. Familial aggregation of hyperemesis gravidarum. Am J Obstet Gynecol 2011;204:230.e1-7.

8. Fejzo MS, Ingles SA, Wilson M, et al. High prevalence of severe nausea and vomiting of pregnancy and hyperemesis gravidarum among relatives of affected individuals. Eur J Obstet Gynecol Reprod Biol 2008;141:13-7.

9. Weigel MM, Weigel RM. The association of reproductive history, demographic factors, and alcohol and tobacco consumption with the risk of developing nausea and vomiting in early pregnancy. Am J Epidemiol $1988 ; 127: 562-70$.

10. Buckwalter JG, Simpson SW. Psychological factors in the etiology and treatment of severe nausea and vomiting in pregnancy. Am J Obstet Gynecol 2002; 186(5 Suppl Understanding):S210-4.

11. Koren G, Clark S, Hankins GD, et al. Effectiveness of delayed-release doxylamine and pyridoxine for nausea and vomiting of pregnancy: a randomized placebo controlled trial. Am J Obstet Gynecol 2010; 203:571.e1-7.

12. Tucker ML, Jackson MR, Scales MD, Spurling NW, Tweats DJ, Capel-Edwards K. Ondansetron: preclinical safety evaluation. Eur J Cancer Clin Oncol 1989;25(Suppl 1):S79-93.

13. Einarson A, Maltepe C, Navioz Y, Kennedy D, Tan MP, Koren G. The safety of ondansetron for nausea and vomiting of pregnancy: a prospective comparative study. BJOG 2004;111:940-3.

14. Zhonging Z. Synopsis of prescriptions of the golden chamber (Jingui Yaolue). Library of Chinese Classics. Middle Island, NY: New World Press; 2008.

15. National Tropical Botanical Garden. Zingiber officinale. Available from: http://ntbg.org/plants/plant_ details.php?plantid=11651. Accessed July 1, 2013.

16. Govindarajan VS. Ginger-chemistry, technology, and quality evaluation: part 1. Crit Rev Food Sci Nutr 1982;17:1-96.

17. Govindarajan VS. Ginger-chemistry, technology, and quality evaluation: part 2. Crit Rev Food Sci Nutr 1982;17:189-258.

18. Grontved A, Brask T, Kambskard J, Hentzer E. Ginger root against seasickness. A controlled trial on the open sea. Acta Otolaryngol 1988;105:45-9.

19. Mowrey DB, Clayson DE. Motion sickness, ginger, and psychophysics. Lancet 1982;1:655-7.

20. Chaiyakunapruk N, Kitikannakorn N, Nathisuwan S, Leeprakobboon K, Leelasettagool C. The efficacy of ginger for the prevention of postoperative nausea and vomiting: a meta-analysis. Am J Obstet Gynecol 2006;194:95-9.

21. Haniadka R, Rajeev AG, Palatty PL, Arora R, Baliga MS. Zingiber officinale (ginger) as an anti-emetic in cancer chemotherapy: a review. J Altern Complement Med 2012;18:440-4.

22. Marx WM, Teleni L, McCarthy AL, et al. Ginger (Zingiber officinale) and chemotherapy-induced 
nausea and vomiting: a systematic literature review. Nutr Rev 2013;71:245-54.

23. Niebyl JR, Goodwin TM. Overview of nausea and vomiting of pregnancy with an emphasis on vitamins and ginger. Am J Obstet Gynecol 2002;186(5 Suppl Understanding):S253-5.

24. Willetts KE, Ekangaki A, Eden JA. Effect of a ginger extract on pregnancy-induced nausea: a randomised controlled trial. Aust N Z J Obstet Gynaecol 2003; 43:139-44.

25. Portnoi G, Chng LA, Karimi-Tabesh L, Koren G, Tan MP, Einarson A. Prospective comparative study of the safety and effectiveness of ginger for the treatment of nausea and vomiting in pregnancy. Am J Obstet Gynecol 2003;189:1374-7.

26. Smith C, Crowther C, Willson K, Hotham N, McMillian $\mathrm{V}$. A randomized controlled trial of ginger to treat nausea and vomiting in pregnancy. Obstet Gynecol 2004;103:639-45.

27. Borrelli F, Capasso R, Aviello G, Pittler MH, Izzo AA. Effectiveness and safety of ginger in the treatment of pregnancy-induced nausea and vomiting. Obstet Gynecol 2005;105:849-56.

28. Abdel-Aziz H, Windeck T, Ploch M, Verspohl EJ. Mode of action of gingerols and shogaols on 5-HT3 receptors: binding studies, cation uptake by the receptor channel and contraction of isolated guineapig ileum. Eur J Pharmacol 2006;530:136-43.

29. Pertz HH, Lehmann J, Roth-Ehrang R, Elz S. Effects of ginger constituents on the gastrointestinal tract: role of cholinergic M3 and serotonergic 5-HT3 and 5-HT4 receptors. Planta Med 2011;77:973-8.

30. Tiran D. Ginger to reduce nausea and vomiting during pregnancy: evidence of effectiveness is not the same as proof of safety. Complement Ther Clin Pract 2012;18:22-5.

31. Basirat Z, Moghadamnia A, Kashifard M, SarifiRazavi A. The effect of ginger biscuit on nausea and vomiting in early pregnancy. Acta Medica Iranica 2009; 47:51-6.

32. Keating A, Chez RA. Ginger syrup as an antiemetic in early pregnancy. Altern Ther Health Med 2002; 8:89-91.

33. Fischer-Rasmussen W, Kjaer SK, Dahl C, Asping U. Ginger treatment of hyperemesis gravidarum. Eur J Obstet Gynecol Reprod Biol 1991;38:19-24.

34. Vutyavanich T, Kraisarin T, Ruangsri R. Ginger for nausea and vomiting in pregnancy: randomized, double-masked, placebo-controlled trial. Obstet Gynecol 2001;97:577-82.

35. Ozgoli G, Goli M, Simbar M. Effects of ginger capsules on pregnancy, nausea, and vomiting. J Altern Complement Med 2009;15:243-6.

36. Backon J. Ginger in preventing nausea and vomiting of pregnancy; a caveat due to its thromboxane synthetase activity and effect on testosterone binding. Eur J Obstet Gynecol Reprod Biol 1991;42:163-4.

37. Srivastava KC. Effect of onion and ginger consumption on platelet thromboxane production in humans. Prostaglandins Leukot Essent Fatty Acids 1989;35: 183-5.

38. Wilkinson JM. Effect of ginger tea on the fetal development of Sprague-Dawley rats. Reprod Toxicol 2000;14:507-12.

39. Weidner MS, Sigwart K. Investigation of the teratogenic potential of a zingiber officinale extract in the rat. Reprod Toxicol 2001;15:75-80.

40. Arfeen Z, Owen H, Plummer JL, Ilsley AH, SorbyAdams RA, Doecke CJ. A double-blind randomized controlled trial of ginger for the prevention of postoperative nausea and vomiting. Anaesth Intensive Care 1995;23:449-52.

41. Meyer K, Schwartz J, Crater D, Keyes B. Zingiber officinale (ginger) used to prevent 8-Mop associated nausea. Dermatol Nurs 1995;7:242-4. 


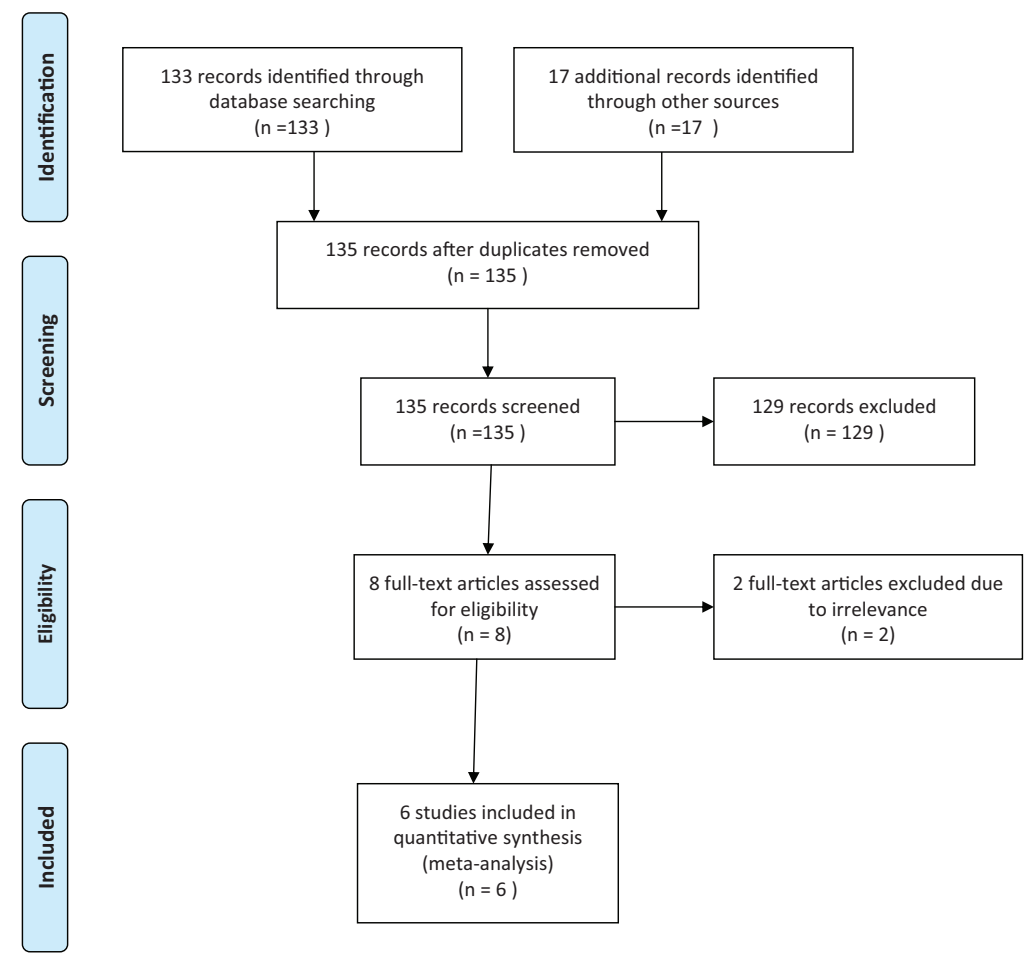

